ISSN $1412-2936$

EISSN 2549-7308

\title{
THEORY OF PLANNED BEHAVIOR PADA E-COMMERCE INTENTION MAHASISWA DI SURABAYA
}

\author{
Okto Aditya Suryawirawan \\ oktoaditya@stiesia.ac.id \\ SEKOLAH TINGGI ILMU EKONOMI INDONESIA (STIESIA) SURABAYA
}

\begin{abstract}
ABSTRAK
Tujuan dari penelitian ini untuk menganalisis pengaruh attitude, subjective norm, perceived behavioral control dan gender terhadap e-commerce intention mahasiswa di Surabaya. Penelitian ini menggunakan sumber data primer yang diperoleh secara langsung dengan menyebarkan kuesioner kepada 103 responden. Metode pengambilan sampel adalah non-probability dengan teknik purposive sampling. Kriteria responden adalah mahasiswa yang menggunakan aplikasi e-commerce setidaknya sebulan sekali. Metode penelitian menggunakan analisis partial least square. Temuan dari penelitian ini adalah attitude memiliki pengaruh positif terhadap e-commerce intention, subjective norm memiliki pengaruh positif terhadap e-commerce intention, perceived behavioral control memiliki pengaruh positif terhadap e-commerce intention. Mahasiswa perempuan memiliki e-commerce intention yang lebih tinggi daripada mahasiswa laki-laki.
\end{abstract}

\begin{abstract}
The purpose of this study is to analyze the influence of attitude, subjective norm, perceived behavioral control and gender towards e-commerce intention of college students in Surabaya. This research uses primary data resources which collected directly by distributing questionnaires to 103 respondents. The sampling method used is nonprobability sampling with purposive sampling technique. The respondents are college students that use e-commerce application at least once a month. The research method used is partial least square and mann-whitney $u$ test. The findings of this study are attitude has a positive effect towards e-commerce intention, subjective norm has a positive effect towards e-commerce intention, perceived behavioral control has a positive effect towards e-commerce intention. Female college students have a higher e-commerce intention compared to male college students.
\end{abstract}

Keyword: Theory of Planned Behavior; Attitude; Subjective Norm; Perceived Behavioral Control; Gender; E-commerce Intention

\section{Pendahuluan}

Perkembangan e-commerce di Indonesia sangat pesat dalam kurun waktu 5 tahun terakhir. Dari 19,8 juta orang di tahun 2014, pengguna ecommerce di Indonesia diperkirakan dapat mencapai 39,3 juta pada tahun 2020 (Ekayanti, 2017). Statistik mencatat bahwa pengguna internet meningkat dengan pesat dari 88,1 juta pengguna di tahun 2014 menjadi 143,26 juta pada tahun 2017 (APJII, 2017). Keberadaan smartphone menjadi salah satu faktor kuat yang menyebabkan fenomena ini dimana $44 \%$ akses internet dilakukan melalui perangkat tersebut (APJIII, 2017). Melalu data statistik diatas juga ditemukan bahwa 98,6\% mengetahui perihal adanya jual beli secara online, 82,2 juta orang pernah mengunjungi situs jual beli online, 32\% layanan yang paling banyak digunakan adalah untuk melakukan pembelian barang, sedangkan hanya $9 \%$ pengguna yang 
melakukan penjualan (APJII, 2016, 2017). Ini menunjukkan bahwa potensi dari perkembangan e-commerce masih sangat besar di Indonesia.

Dengan perkembangan e-commerce dan potensinya yang masih sangat besar di Indonesia, diharapkan dapat menjadi solusi dari masih tingginya angka pengangguran yang ada di Indonesia. Statistik menunjukkan bahwa persentase pengangguran terhadap angkatan kerja di Indonesia berada di angka 5,34\% pada Agustus 2018. Meski terdapat penurunan dari data pada Agustus 2017 yang sebesar $5,50 \%$, angka tersebut meningkat dari Februari 2018 yang hanya 5,13\% (Badan Pusat Statistik, 2018). Ini menunjukkan bahwa masih ada hampr 7 juta orang Indonesia yang belum memperoleh pekerjaan. Dengan keterbatasan lapangan kerja yang ada, penciptaan lapangan kerja baru melalui kewirausahaan khususnya e-commerce diharapkan dapat membantu mengurangi lebih banyak angka pengangguran tersebut dari tahun ke tahun.

Melalui perkembangan teknologi yang dapat mengakomodir pendirian usaha melalui e-commerce, penelitian ini mecoba menganalisis tentang niatan seseorang untuk mendirikan usaha melalui e-commerce. Theory of planned behavior menyatakan bahwa intention yang kemudian akan diikuti oleh action ditentukan oleh attitude, subjective norm dan perceived behavioral control (Bird, 1988; Katz dan Gartner, 1988; Ajzen, 1991). Penelitian ini, diharapkan dapat melihat dampak signifikan dari theory of planned behavior pada niatan untuk mendirikan usaha melalui e-commerce dengan menggunakan aplikasi online shop, demi mewujudkan pengurangan terhadap tingkat pengangguran dan peningkatan ekonomi di Indonesia secara umum.

\section{Tinjauan Pustaka}

Intention diartikan sebagai fungsi dari kepercayaan yang memberikan hubungan antara rasa percaya dengan perilaku yang mengikutinya (Ajzen, 1991). Ajzen (1991) juga menyatakan bahwa niatan terhadap sebuah perilaku dapat menjadi indikator yang kuat terhadap perwujudan perilaku tersebut.

Eagly dan Chaiken (1993)
menyatakan bahwa attitude adalah
kecenderungan untuk melakukan
evaluasi baik positif atau negatif
terhadap sebuah masalah atau subjek.
Karakter psikis tersebut ada pada setiap
manusia dalam bentuk observasi dan
evaluasi kritis. Shook dan Bratianu
(2010) menyatakan bahwa attitude
seseorang terhadap sesuatu bergantung
pada outcome, semakin positif outcome
yang dihasilkan maka semakin baik
persepsi orang tersebut dan semakin
tinggi niatan orang tersebut untuk
melakukan suatu kegiatan. Dari
pemaparan diatas maka hipotesis pada
penelitian ini adalah sebagai berikut:

$\mathrm{H} 1$ : attitude berpengaruh positif signifikan terhadap e-commerce intention mahasiswa di Surabaya

$\begin{gathered}\text { Subjective norm adalah sejauh } \\ \text { seseorang atau individu }\end{gathered}$
mana (adak mendukung)
mendukung (atau tidak
hasil dari tindakan tertentu (Fishbein \&
Ajzen, 1975). Dalam serangkaian
penelitian yang pernah dilakukan
subjective norm diukur dengan
menanyakan responden sejauh mana
keluarga, teman, atau kolega yang
mereka miliki, mendukung aktifitas yang
mereka lakukan, yang dalam penelitian
ini khususnya adalah aktifitas pendirian
usaha (Linan dan Chen, 2009; Ajzen,
2001). Karena persepsi dari serangkaian
kelompok individu diatas cenderung
subyektif, maka kemudian disebut
sebagai subjective norm (Fishbein dan
Ajzen, 1975). Terlepas dari konsep
theory of planned behavior dan
pengaruhnya terhadap intention (Ajzen,


1991), secara umum subjective norm yang merupakan bagian dari theory of planned behavior cenderung memiliki hubungan yang inkonsisten terhadap intention (Krueger et al., 2000). Alasan dibalik inkonsistensi tersebut adalah informasi yang menjadi bagian dari subjective norm telah ada didalam keputusan untuk melakukan sesuatu atau menunjukkan perilaku tertentu (Ham et al., 2015). Oleh karena itu dibutuhkan penelitian lebih lanjut terkait dengan hubungan antara subjective norm dengan intention. Dari pemaparan diatas maka hipotesis pada penelitian ini adalah sebagai berikut:

$\mathrm{H} 2$ : subjective norm berpengaruh positif signifikan terhadap e-commerce intention mahasiswa di Surabaya

Theory of planned behavior menyatakan bahwa perceived behavioral control dan behavioral intention adalah alat yang baik untuk memprediksi pencapaian seorang individu akan sesuatu (Ajzen, 1991). Perceived behavioral control adalah persepsi seorang individu tentang kemudahan atau kesulitan yang dihadapi ketika melakukan sesuatu (Ajzen, 1991), yang dalam penelitian ini mengenai bagaimana mendirikan ataupun menjalankan suatu usaha. Semakin besar perceived behavioral control, semakin kuat niatan seseorang untuk menunjukkan perilaku tertentu. Penelitian sebelumnya juga menyatakan bahwa perceived behavioral control mampu memprediksi secara langsung perilaku dan niatan karena perasaan mampu mengendalikan sesuatu meningkatkan kemauan seseorang untuk mengeluarkan usaha yang lebih untuk mencapai kesuksesan dalam suatu hal (Armitage dan Conner, 2001). Dari pemaparan diatas maka hipotesis pada penelitian ini adalah sebagai berikut:

H3: perceived behavioral control berpengaruh positif signifikan terhadap e-commerce intention mahasiswa di Surabaya

Serangkaian penelitian sebelumnya menyatakan bahwa lelaki dan perempuan tidak terpengaruh oleh hal yang serupa terkait faktor-faktor yang berhubungan dengan entrepreneurship, baik dari pengalaman pribadi maupun entrepreneur yang menjadi panutan atau role model (Kickul et al., 2008; Van Auken et al., 2006). Maka dari itu pada penelitian ini diuji pula apakah perbedaan gender juga berpengaruh terhadap entrepreneurial intention hipotesis sebagai berikut:

$\mathrm{H} 4$ : mahasiswa memiliki e-commerce intention yang lebih tinggi dibandingkan mahasiswi

Penelitian ini mengacu pada penelitian sebelumnya yang dilakukan oleh Dinc dan Budic (2016). Berdasarkan penelitian tersebut ditemukan bahwa personal attitude dan perceived behavioural control berpengaruh positif signifikan terhadap entrepreneurial intention. Penelitian ini juga mengacu pada penelitian sebelumnya yang dilakukan oleh Engle et al. (2011). Berdasarkan penelitian tersebut perbedaan gender ditemukan memiliki dampak terhadap entrepreneurial intention. Maka penelitian ini bertujuan untuk mengetahui apakah hasil penelitian ini nantinya akan memperkuat hasil penelitian tersebut atau justru sebaliknya.

Kerangka konseptual dapat dilihat pada Gambar 1.

\section{Metode}

Dalam penelitian ini, metode pengambilan sampel yang digunakan adalah metode non-probability purposive sampling, yaitu kuisioner diberikan kepada mahasiswa di Surabaya yang pernah menggunakan aplikasi berbelanja online karena mahasiswa adalah salah 
ISSN 1412-2936

EISSN 2549-7308

satu kelompok pengguna internet dengan persentase terbesar (APJII, 2017).

Attitude diukur dengan mengunakan empat indikator yang digunakan oleh Hsu et al. (2006). Subjective norm diukur dengan menggunakan tiga indikator yang digunakan oleh Hsu et al. (2006). Perceived behavioral control diukur dengan menggunakan tiga indikator yang digunakan oleh Hsu et al. (2006). E-commerce Intention diukur dengan menggunakan tiga indikator yang digunakan oleh Hsu et al (2006).

Penilaian terhadap pernyataan responden diukur dengan menggunakan skala yang telah dimodifikasi menjadi 4 tingkat untuk mengeliminasi kelemahan yang dikandung oleh skala 5 tingkat, karena seringkali poin tengah atau poin netral digunakan responden ketika mereka tidak yakin dengan pilihannya, serta untuk menghindari central tendency sehingga dapat diketahui dengan jelas arah dari jawaban responden (Kulas, 2008; Tsang, 2012).

Menurut Hair et al. (2014), rekomendasi ukuran sample dengan statistical power sebesar $80 \%$ pada penelitian yang memiliki 3 variabel independen adalah 100 responden untuk tingkat signifikansi $10 \%$ dengan $R^{2}$ setidaknya 0,1. Maka dari itu peneliti memerlukan 100 responden untuk melakukan pengujian. Metode penelitian menggunakan analisis partial least square dan mann-whitney u test.

\section{Hasil dan Pembahasan}

Data dari penelitian ini diperoleh dari penyebaran kuesioner kepada responden penelitian secara online. Responden pada penelitian ini adalah mahasiswa di Surabaya yang pernah menggunakan aplikasi berbelanja online, dengan jumlah sampel sebanyak 103 orang.
Tabel 1. Profil Responden

\begin{tabular}{lc}
\hline \multicolumn{1}{c}{ Jenis Kelamin } & Jumlah \\
\hline Laki-Laki & 31 \\
Perempuan & 72 \\
Total & 103 \\
\hline \multicolumn{1}{c}{ Usia (Tahun) } & Jumlah \\
\hline 19-21 & 78 \\
22-23 & 20 \\
24-25 & 5 \\
Total & 103 \\
\hline \multicolumn{1}{c}{ Frekuensi } & Jumlah \\
\hline Penggunaan & 35 \\
Lebih 1x/hari & 25 \\
1x/hari & 28 \\
1x/minggu & 15 \\
1x/bulan & 103 \\
Total & \\
\hline
\end{tabular}

Tabel 1 menunjukkan bahwa dari 103 responden terdapat 69,90\% responden perempuan, sedangkan responden laki-laki hanya 30,1\%. Terdapat $75,7 \%$ responden berusia 19 21 tahun, terdapat $19,4 \%$ responden berusia 22-23 tahun, sedangkan responden berusia 24-25 tahun hanya 0,4\%. Terdapat 33,9\% responden membuka aplikasi berbelanja online lebih dari 1 kali per hari, 24,2\% responden membuka aplikasi berbelanja online 1 kali per minggu, 27,1\% responden membuka aplikasi berbelanja online 1 kali per hari, dan hanya 14,8\% responden yang membuka aplikasi berbelanja online 1 kali per bulan.

Berdasarkan hasil dari uji goodness of fit yang ada pada Tabel 2, indikator variabel yang memiliki nilai outer loading $<0,40$ telah di eleminisasi dan akar AVE memiliki nilai yang lebih besar dari korelasinya sehingga 
discriminant validity pada penelitian ini dapat dikatakan sudah baik. Nilai composite reliability seluruhnya diatas > 0,50 sehingga model penelitian dapat dikatakan reliabel. Menurut Hair et. al. (2014) penghapusan indikator pada variabel yang memiliki outer loading 0,40 - 0,70 hanya perlu dilakukan apabila dapat meningkatkan nilai composite reliability dan AVE hingga mencapai nilai threshold-nya yaitu 0,50. Setelah dilakukan penghapusan pada indikator varabel yang memiliki nilai outer loading $<0,40$, composite reliability cenderung meningkat dan tidak terdapat variabel yang memiliki nilai $\mathrm{AVE}<0,50$, sehingga dapat dilanjutkan ke tahapan pengujian selanjutnya. $R^{2}$ untuk variabel $e$ commerce intention sebesar 0.442 yang berarti e-commerce intention dapat dijelaskan oleh attitude, subjective norm dan perceived behavioral control sebesar $44,2 \%$, sedangkan sisanya dijelaskan oleh variabel lainnya diluar penelitian ini.

Tabel 3. Path Coefficient

\begin{tabular}{lcc}
\hline $\begin{array}{c}\text { Path } \\
\text { Coefficient }\end{array}$ & $\begin{array}{c}\text { Original } \\
\text { Sample }\end{array}$ & $\begin{array}{c}\text { T- } \\
\text { Statistic }\end{array}$ \\
\hline Att $->\mathrm{El}$ & 0.0906 & 0.7086 \\
$\mathrm{PBC}->\mathrm{EI}$ & 0.2449 & 2.4943 \\
$\mathrm{SN}->\mathrm{EI}$ & 0.5003 & 3.6183 \\
\hline
\end{tabular}

Dari hasil pengujian hipotesis yang ada pada Tabel 3 didapatkan hasil bahwa terdapat hubungan positif tidak signifikan antara attitude (Att) dengan ecommerce intention (EI) dari nilai original sample Att>El sebesar 0.0906 dan nilai T Statistik Att>El sebesar 0.7086 atau < 1,96. Terdapat hubungan positif signifkan antara subjective norm (SN) dengan e-commerce intention (EI) dari nilai original sample $\mathrm{SN}>\mathrm{El}$ sebesar 0,5003 dan nilai $T$ Statistik $S N>E I$ sebesar 3,6183 atau $>1,96$. Terdapat hubungan positif signifikan antara perceived behavioral control (PBC) dengan e-commerce intention (EI) dari nilai original sample $\mathrm{PBC}>\mathrm{El}$ sebesar 0,2449 dan $T$ Statistik $S N>E I$ sebesar 2,4943 atau > 1,96. Mann-whitney test menghasilkan nilai signifikansi sebesar $0,013<0,05$. Dapat disimpulkan bahwa terdapat perbedaan yang signifikan antara E-Commerce Intention pada responden laki-laki dan E-Commerce Intention pada responden perempuan. $E$ Commerce Intention pada responden perempuan lebih tinggi daripada $E$ Commerce Intention pada responden laki-laki, ditunjukkan dengan rerata $E$ Commerce Intention masing-masing sebesar 3,76 dan 3,42. Berdasarkan hasil ini hipotesis penelitian yang menduga mahasiswa laki-laki memiliki $E$ Commerce Intention yang lebih tinggi dibandingkan mahasiswa perempuan, tidak terbukti.

Hasil pengujian hubungan antara attitude dengan e-commerce intention

Tabel 2. Goodnes of Fit

\begin{tabular}{|c|c|c|c|c|c|c|c|}
\hline $\begin{array}{c}\text { Goodness of } \\
\text { Fit }\end{array}$ & Loading*) & AVE*) & $\sqrt{ } \mathbf{A V E}$ & $\begin{array}{c}\text { Composite } \\
\text { Reliability*) }\end{array}$ & $\begin{array}{c}\text { Composite } \\
\text { Reliability**) }\end{array}$ & AVE**) & R-Square \\
\hline Att: Att1 & 0.413 & 0.437 & 0.661 & 0.712 & 0.779 & 0.565 & \\
\hline Att 2 & 0.195 & & & & & & \\
\hline Att3 & 0.838 & & & & & & \\
\hline Att4 & 0.915 & & & & & & \\
\hline EI:EI1 & 0.929 & 0.778 & 0.882 & 0.913 & 0.913 & 0.778 & \\
\hline EI2 & 0.838 & & & & & & 0.442 \\
\hline EI3 & 0.876 & & & & & & \\
\hline PBC: PBC1 & 0.527 & 0.365 & 0.604 & 0.689 & 0.701 & 0.545 & \\
\hline PBC2 & 0.899 & & & & & & \\
\hline PBC3 & 0.099 & & & & & & \\
\hline SN:SN1 & 0.636 & 0.567 & 0.753 & 0.838 & 0.838 & 0.567 & \\
\hline
\end{tabular}

Makro, JưfHąı Maraffetmen \& Kewirausahaan, Vol. 4 No. 2 | November 2019

SN4 0.825

*: original value

$* *$ :after elimination of loading $<0.40$ 
adalah positif tidak signifikan. Hasil positif tersebut secara statistik sejalan dengan karakteristik jawaban dari responden yaitu sangat tinggi. Dari sikap responden yang dalam penelitian ini keseluruhannya adalah mahasiswa menunjukkan hasil yang sangat positif, mendukung hasil analisis statistik yang terbukti mendukung pengaruh attitude terhadap niatan mereka untuk mendirikan usaha dibidang e-commerce. $\mathrm{Hal}$ ini sejalan dengan penelitian sebelumnya yang dilakukan oleh Dinc dan Budic (2016) yang menemukan pengaruh positif attitude terhadap entrepreneurial intention.

Hasil pengujian hubungan antara subjective norm dengan e-commerce intention adalah positif signifikan. Hasil positif tersebut secara statistik sejalan dengan karakteristik jawaban dari responden yaitu sangat tinggi. Persepsi penerimaan yang positif dari orang-orang yang ada disekitar responden yang seluruhnya adalah mahasiswa secara positif mempengaruhi niatan mereka untuk mendirikan usaha khususnya dibidang e-commerce. Hal ini sejalan dengan serangkaian penelitian sebelumnya (Dinc dan Budic, 2016; Karimi et al., 2014; Mat et al., 2015) yang menemukan pengaruh positif signifkan subjective norm terhadap entrepreneurial intention.

Hasil pengujian hubungan antara perceived behavioral control dengan ecommerce intention adalah positif signifikan. Hasil positif tersebut secara statistik sejalan dengan karakteristik jawaban dari responden yaitu sangat tinggi. Responden yang dalam penelitian ini keseluruhannya adalah mahasiswa, memiliki persepsi yang sangat positif terhadap niatan mendirikan e-commerce. $\mathrm{Hal}$ ini sejalan dengan serangkaian penelitian sebelumnya (Dinc dan Budic, 2016; Karimi et al., 2014; Robledo et al., 2015) yang menemukan pengaruh positif signifkan perceived behavioral control terhadap entrepreneurial intention.

Hasil pengujian menunjukkan bahwa terdapat perbedaan yang signifikan pada e-commerce intention antara mahasiswa dan mahasiswi, hal ini sejalan dengan penelitian sebelumnya yang menyatakan bahwa perbedaan gender memiliki pengaruh terhadap entrepreneurial intention (Engle et al., 2011; Hatak et al., 2015). Berlawanan dengan serangkaian penelitian sebelumnya yang menyatakan bahwa karir sebagai entrepreneur didominasi oleh laki-laki (Santos et al., 2014; Canizares et al., 2010; Yordanova dan Tarrazon, 2010), penelitian ini menemukan bahwa perempuan dalam hal ini mahasiswi, memiliki entrepreneurship intention yang lebih tinggi daripada mahasiswa. $\mathrm{Hal}$ ini menunjukkan adanya inkonsistensi terkait dengan faktor-faktor yang dapat mempengaruhi entrepreneurship sebagai pilihan karir dari kedua gender, dimana terdapat penelitian yang menyatakan bahwa rendahnya gender stereotype dan tingginya masculine orientation yang tidak terbatas oleh gender, dapat mempengaruhi niatan khususnya wanita untuk mendirikan usaha (Sweida dan Reichard, 2013; Mueller dan Dato-on, 2008). Haus et al. (2013) juga menyatakan bahwa terlepas dari perbedaan motivasi yang signifikan dalam mendirikan usaha, tidak ditemukan dengan jelas adanya perbedaan dalam pendirian usaha itu sendiri antara responden laki-laki dan perempuan. Edukasi juga dapat menjadi faktor penentu niatan mahasiswi untuk mendirikan usaha, penelitian yang dilakukan oleh Lo dan Law (2012) menyatakan bahwa terlepas niatan pendirian usaha yang lebih tinggi pada laki-laki dibandingkan dengan wanita, setelah menerima edukasi seputar entrepreneurship justru menunjukkan 
ISSN 1412-2936

EISSN 2549-7308

respon yang serupa terhadap pendirian usaha.

\section{Kesimpulan dan Rekomendasi}

Penelitian ini dapat menunjukkan bahwa dengan adanya perkembangan teknologi e-commerce yang memudahkan pengguna untuk memasarkan usaha, perempuan memiliki niatan yang lebih besar untuk menjadi entrepreneur baru, sebuah pilihan karir yang sebelumnya didominasi oleh lakilaki. Fokus dari penciptaan produk dan pendirian usaha adalah bagaimana dapat menciptakan lapangan kerja baru dan mengurangi tingkat pengangguran yang ada di Indonesia. Oleh karena itu dengan semakin rendahnya stereotype barrier yang menghalangi perempuan untuk mendirikan usaha, diharapkan dapat meningkatkan jumlah usaha, yang pada akhirnya menciptakan lebih banyak lapangan kerja dan menyerap lebih banyak tenaga kerja. Bagi institusi pendidikan penelitian ini diharapkan mampu memberikan wawasan bahwa porsi perempuan yang mempertimbangkan pendirian usaha sebagai pilihan karirnya semakin besar, sehingga potensi dari mereka perlu digali lebih dalam agar tidak hanya terbatas pada niatan pendirian usaha yang tinggi, tetapi juga secara riil mewujudkan pendirian usaha itu sendiri.

Berdasarkan pembahasan dan simpulan diatas, penelitian ini ingin memberikan rekomendasi bagi akademisi untuk penelitian selanjutnya. Penelitian ini hanya dilakukan terhadap sample sejumlah 103 orang, kedepannya penelitian yang lebih lanjut dapat dilakukan kepada lebih banyak orang sehingga dapat merepresentasikan dengan lebih baik populasi dan sampel yang digunakan. Penelitian ini juga dilakukan terbatas dikalangan mahasiswa, sehingga penelitian selanjutnya diharapkan mampu menyentuh lebih banyak elemen masyarakat yang lain. Kedepannya penelitian akan lebih baik apabila terfokus pada satu bidang usaha dan melalui satu aplikasi yang relevan dengan bidang usaha daripada beragam bidang usaha dan melalui beragam aplikasi.

\section{Referensi}

Ajzen, I. 1991. The theory of planned behavior. Organizational Behavior and Human Decision Processes. Vol. 50(2): 179-211

Ajzen, I. 2001. Nature and Operation of Attitudes. Annual Review of Psychology. Vol. 52: 27-58

Armitage, C. J., M. Conner, 1999. Distinguishing Perception of Control from Self-Efficacy: predicting Consumption of a Low Fat Diet using the Theory of Planned Behavior. Journal of Applied Social Psychology. Vol. 29: $72-90$

Armitage, C. J., M. Conner, J. Loach, D. Willets.1999. Different Perception of Control: Applying an Extended Theory of Planned Behavior to Legal and Illegal Drug Use. Basic and Applied Social Psychology. Vol. 21: 301 316

Artmitage, C., M. Conner. 2001. Efficacy of the Theory of Planned Behavior: A Meta-Analytical Review. British Journal of Social Psychology. Vol. 40: 471-499

Asosiasi Penyelenggara Jasa Internet Indonesia. 2016. Infografis Penetrasi \& Perilaku Pengguna Internet Indonesia. Survey 2016.

Asosiasi Penyelenggara Jasa Internet Indonesia. 2017. Infografis Penetrasi \& Perilaku Pengguna Internet Indonesia. Survey 2017.

Badan Pusat Statistik, 2018. Berita Resmi Statistik Agustus 2018: Tingkat Pengangguran Terbuka (TT) Sebesar 5.34 Persen. 
Diakses 19 Januari 2019, http://www.bps.go.id

Bandura, 1977. Self-efficacy: Toward a Unifying Theory of Behavioral Change. Psychological Review. Vol. 84: 191-215

Bandura, A. 1993. Perceived SelfEfficacy in Cognitive Development and Functioning. Educational Psychology. Vol. 28(2): 117-148

Bandura, A. 1997. Self-efficacy: The Exercise of Control. New York: Freeman

Bandura, A. 1999. A Social Cognitive Theory of Personality. New York: Guilford Publications

Bandura, A. 2002. Social Cognitive Theory in Cultural Context. Journal of Applied Psychology: An International Review. Vol. 51: 269-290

Bird, B., $1988 . \quad$ Implementing Entrepreneurial Ideas: The Case for Intention. Academy of Management Review. Vol. 13:442-453

DaBusiness Dictionary, 2019. Attitude. Diakses 19 Januari 2019, http://www.businessdictionary.c om

Canizares, S. M. S., F. J. F. Garcia. 2010. Gender differences in entrepreneurial attitudes. Equality, Diversity and Inclusion: An International Journal. Vol. 29(8): 766-786

Ciputra, A. Tanan, A. Waluyo. 2011. Ciputra Quantum Leap 2: Kenapa dan Bagaimana Entrepreneurship Mengubah Masa Depan Bangsa dan Masa Depan Anda. Jakarta: Elex Media Komputindo

Chen, G., S. M. Gully, D. Eden. 2001. Validation of a New General Self-efficacy Scale. Organizational Research Method. Vol. 4(1):62-83

Dana, L., 2004. Handbook of Research on International Entrepreneurship. Cheltenham: Edward Elgar
Davis, F. D., Bagozzi, R. P. dan Warshaw, P. R. 1989. User Acceptance of Computer Technology: A Comparison of Two Theoretical Models. Management Science. Vol. 35(8): $982-1003$

Dinc M. S., S. Budic, 2016. The Impact of Personal Attitude, Subjective Norm and Perceived Behavioral Control on Entrepreneurial Intentions of Women. Eurasian Journal of Business and Economics. Vol. 9(17): 23-35

Eagly, A. H., S. Chaiken. 1993. The Psychology of Attitudes. Orlando: Harcourt Brace Jovanovich College Publishers

Ekayanti, Y. 2016. E-Commerce Industry One Step Ahead: How to get sales leads. Diakses tanggal 19 Januari 2019,

https://adways.co.id/blog/ecommerce-industry-one-stepahead-how-to-get-sales-leads

Engle, R. L., C. Schlaegel, S. Delanoe, 2011. The Role of Social Influence, Culture and Gender on Entrepreneurial Intent. Journal of Small Business and Entrepreneurship. Vol. 24(4): 461-492

Fishbein, M., I. Ajzen. 1975. Belief, Attitude, Intention and Behavior: An Introduction to Theory and Research. New York: AddisonWesley

Hair, J. F., G. T. M. Hult, C. M. Ringle, M. Sarstedt. 2014. A Primer on Partial Least Squares Structural Equation Modeling (PLS-SEM). California: SAGE Publications, Inc.

Ham, M., M. Jeger, A. F. Ivković. 2015. The Role of Subjective Norm in Forming the Intention to Purchase Green Food. Economic Research. Vol. 28(1): 738-748

Hatak, I., R. Harms, M. Fink. 2015. Age, job identification, and entrepreneurial intention. Journal of Management Psychology. Vol. 30(1): 38-53 
ISSN 1412-2936

EISSN 2549-7308

Haus, I., R. Isidor, H, Steinmetz, R. Kabst. 2013. Gender Effects on Entrepreneurial Intention: A Meta-Analytical Structural Equation Model. International Journal of Gender and Entrepreneurship. Vol. 5(2): 130-156

Hsu, D. K., K. Burmeister-Lamp, S. A. Simmons, M-D. Foo, M. C. Hong, J. D. Pipes. 2018. "I know I can, but I don't fit": Perceived fit, self-efficacy, and entrepreneurial intention. Journal of Business Venturing. Vol. 34(2): 311-326

Hsu, M., C. Yen, C. Chiu, C. Chang. 2006. A Longitudinal Investigation of Continued Online Shopping Behavior: An Extension of the Theory of Planned Behavior. International Journal of Human-Computer Studies. Vol. 64: 889-904

Kakkonen, M-L. 2018. First-year business students' entrepreneurial attitudes. $4^{\text {th }}$ International Conference on Higher Education Advances. 257-265

Katz, J., W.B. Gartner. 1988. Properties of Emerging Organizations. Academy of Management Review. Vol. 13(3): 429-441

Kickul, J., F. Wilson, D. Marlino, S. D. Barbosa. $2008 . \quad$ Are Misalignment of Perceptions and Self-efficacy Causing Gender Gaps in Entrepreneurial Intentions among Our Nation's Teen. Journal of Small Business and Enterprise Development. Vol. 15(2): 321-335

Krueger, N. F., M. Reilly, A. Carsrud. 2000. Competing Models of Entrepreneurial Intentions. Journal of Business Venturing. Vol. 15(2): 411-432

Kulas, J. T. 2008. SPSS Essentials: Managing and Analyzing Social Sciences Data. New Jersey: John Wiley \& Sons

Linán, F., Y. W. Chen. 2009. Development and Cross-
Cultural Application of a Specific Instrument to Measure Entrepreneurial Intentions. Entrepreneurship Theory and Practice. Vol. 24(3): 5-24

Lo, C., K. Law. 2012. Comparing the Entrepreneurial Intention between Female and Male Engineering Students. Journal of Women's Entrepreneurship and Education. Vol. 1(2): 28-51

Mat, S. C., S. M. Maat, N. Mohd. 2015. Identifying Factors that Affecting the Entrepreneurial Intention among Engineering Technology Students. Procedia - Social and Behavioral Science. Vol (211): 1016-1022

Mueller, S. L. 2004. Gender Gaps in Potential for Entrepreneurship Across Countries and Cultures. Journal of Developmental Entrepreneurship. Vol. 9(3): 199-220

Mueller, S. L., M. C. Dato-On. 2008. Gender-role Orientation as a Determinant of Entrepreneurial Self-efficacy. Journal of Developmental

Entrepreneurship. Vol. 13(1): 320

Robledo, J. L., M. V. Aran, V. M. Sanchez, M. A. R. Molina. 2015. The moderating role of gender on entrepreneurial intententions: A TPB perspective. Intangible Capital. Vol. 11(1): 92-118

Romer, P. 1994. The Origins of Endogenous Growth. Journal of Economics Perspective. Vol. 8(1): 3-22

Santos, F. J., M. A. Roomi, F. Linan. 2014. About Gender Differences and the Social Environment in the Development of Entrepreneurial Intentions. Journal of Small Business Management. Vol. 54: 49-66

Shook, C. L., C. Bratianu. 2010. Entrepreneurial intent in a transitional economy: an application of the theory of planned behavior to Romanian students.
International 
ISSN 1412-2936

EISSN 2549-7308

Entrepreneurship

and

Management Journal. Vol 6(3):

231-247

Sweida, G. L., R. J. Reichard. Gender stereotyping effects on entrepreneurial self-efficacy and high-growth entrepreneurial intention. Journal of Small Business and Enterprise Development. Vol. 20(2): 296313

Tsang, K. K. 2012. The Use of Midpoint on Likert Scale: The Implication for Educational Research. Hong Kong Teachers' Centre Journal. Vol. 11: 121-130

Van Auken, H., F. Fry, P. Stephens. 2006. The Influence of Role Models on Entrepreneurial Intentions. Journal of Developmental Entrepreneurship. Vol. 11(2): 157-167

Yordanova, D. I., M-A. Tarrazon. 2010. Gender Differences

in Entrepreneurial Intentions: Evidence from Bulgaria. Journal of Developmental Entrepreneurship. Vol. 15(3): 2 